\title{
The Psychological and Social Effects of COVID-19 Outbreak and its Coping Strategies: An Overview and Personal Reflections
}

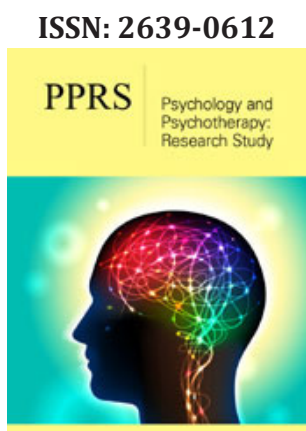

*Corresponding author: El-Zraigat I, Department of counseling and special education, The University of Jordan, Amman, Jordan

Submission: 望 July 25, 2020

Published: 監August 20, 2020

Volume 4 - Issue 1

How to cite this article: El-Zraigat I* Mubarak Alshammari. The Psychological and Social Effects of COVID-19 Outbreak and its Coping Strategies: An Overview and Personal Reflections. Psychol Psychother Res Stud. 4(1). PPRS. 000578. 2020 DOI: 10.31031/PPRS.2020.04.000578

Copyright@ El-Zraigat I, This article is distributed under the terms of the Creative Commons Attribution 4.0 International License, which permits unrestricted use and redistribution provided that the original author and source are credited.

\section{El-Zraigat I* and Mubarak Alshammari}

Department of counseling and special education, The University of Jordan, Amman, Jordan

\begin{abstract}
The prevalence of COVID-19 has had a negative impact on psychological and social aspects such as anxiety and fear of spreading the virus, lack of social activities, family conflicts, boredom and stress. To meet these challenges, it is possible to use various strategies to reduce their negative impacts like relaxation, selfcontrol, problem solving, cognitive reconstruction, social support network development.
\end{abstract}

Keywords: COVID-19, Psychological and social effects, Coping strategies

\section{An Overview}

Coronavirus disease (COVID-19) is an infectious respiratory disease caused by a newly discovered coronavirus. The virus mainly spreads through saliva drops or nasal secretions $[1,2]$. In addition to the negative effect of the virus on a person's health, it also has psychological effects, as these effects vary according to several factors, which are linked to the psychological and personal characteristics of the person and the effect of others surrounding the person, environmental conditions and health protection factors. The rapid spread of the COVID-19 pandemic in the world has caused a great degree of fear and anxiety in the population in general and among certain groups in particular, such as the elderly, caregivers and people with underlying health conditions. Perhaps the most prominent effect is the high levels of tension or anxiety.

Also, measures and effects may lead to quarantine, which may lead to high levels of loneliness, depression, alcohol and harmful drug use, self-harm or suicidal behavior [3]. Public health measures, such as social distance, can make people feel isolated and lonely and this may be one of the causes of stress, anxiety and sadness. Stress during a virus outbreak can also cause fear and concern for personal and other people's health, financial situation or job, or loss of support services. In addition to changes in sleep habits, eating or interests' patterns, exacerbation of chronic health problems and mental health conditions, and increased use of tobacco and/or alcohol [4]. However, Güzel P [5] indicated that the virus caused emotional and psycho-social effects on people who stay at home for some time due to the measures taken to prevent the spread of COVID-19 epidemic. Hagerty \& Williams [6] noted that the crisis of COVID-19 greatly threatens our basic human need for human communication, which may act as an environmental factor affecting biological, behavioral, and environmental aspects, and this reflects the negative impact on mental health. Furthermore, Serafini et al. [7] reported that COVI19 led to socio-economic crises and psychological disorders of varying types and severity.

Vindegaard \& Benros [8] emphasized the need for research to assess direct neuropsychiatric consequences and indirect effects on mental health to improve treatment and plan mental health care and preventive measures during possible subsequent epidemics. Also, Talton [9] discussed tips to help achieve mental health such as staying in touch, busy, 
exercising, being calm, managing information intake, maintaining routine, and sleeping well. In addition, Cheng [10] suggested some measures that may improve the mental health of the people during COVID-19 and enhance the educational process.

\section{The Methodology}

The current study is a theoretical study that attempts to shed light on the psychological and social effects of COVID-19 outbreak and discuss some possible methods for coping with it.

The study tried to answer the following two questions:

a. What are the expected psychological and social effects of COVID-19 on individuals?

b. What are coping strategies that may help in dealing with the psychological and social effects of COVID-19?

\section{The Result}

\section{Personal reflections}

In this section, we discuss the aspects of influence and strategies for dealing with the psycho-social effects of COVID-19.

\section{Fear and anxiety about the spread of the virus}

The rapid spread of the virus and its transmission between countries has led to anxiety among individual. The anxiety comes as a result of the fear of virus infection especially the process of rapid spread and the increase in the number of infected cases in most countries [11-13]. The anxiety may worsen and increase in intensity due to the health effects that may weaken the performance of the body apparatuses, especially among people with low immunity system or who suffer from chronic diseases of the heart, respiratory system, diabetes, asthma and other diseases. Furthermore, the anxiety may result from fear of death when infected with the virus. The treatment of anxiety and fear by following the prevention measures issued by several health organizations or institutes. In addition to knowing about spread of the virus and avoid infection. Anxiety and fear accompany instances of stress and confusion with thinking and behavior, so it is appropriate to develop positive thoughts and use techniques of relaxation, cognitive reconstruction, strategies of self-control, self-regulation, and social distance.

\section{Fear of stigma}

The stigma results from the description of the others to infected person and stay away from visits and avoid communication $[14,15]$. Here, the establishment social support groups throughout WhatsApp and other smart apps such as visual communication apps that may help in achieving adjustment and improve the mental health, as well as keep the person in a state of social contact with others.

\section{Stress}

The spread of the virus has led to countries resorting to implementing health, domestic, and community quarantine systems. Of course, living with family members contributes to deepening mutual understanding between them, identifying each other's characteristics, discovering interests, and so forth [16]. However; the continuation of this procedure for long periods of time resulted in psychological stress, boredom, a strong desire to go outside home and practice usual community activities. May it is appropriate using of problem-solving strategies and dealing with negative thoughts by identifying and replacing them with positive ones, using positive self-talk, self-regulation, relaxation and cognitive reconstruction to avoid psychological stress, as well as establishing social support networks.

\section{The family's concern for the children's educational future}

The virus caused to closure of schools and educational institutions, and in some countries a switch was made to use distance education to follow the educational process. However, some families may not have sufficient or appropriate experience to do so, especially as this has placed a great responsibility on the role that parents, and children must play [17-19]. Here it is appropriate to develop personal skills in aspects of educational technology to provide support and assistance needed by children as well as seeking help from those involved in distance education. In addition to providing learning resources and internet packages in order to support children educationally and follow-up procedures to implement homework and access the curricula.

\section{Conflicts within the family}

Perhaps staying for a long time at home and restricting going out of the house increases psychological stress, this may lead to conflicts between family members and husbands. Conflict forms may take hard debate; impose voices in the debate, and instances of anger [20]. In these cases, it is appropriate using strategies of self-control, creative problem-solving, relaxation, and agreeing to discuss aspects of the problem using purposeful discussion methods and respecting the views and perceives of the problem from the perspective of others in terms of its dimensions, causes and solution.

\section{Boredom of the daily routine and frustration}

Living and staying at home for a long-time result in boredom in the practice of daily activities. This is due to of repeated daily activities and restrictions imposed on the practice of various social and community activities. In these cases, it is appropriate to develop self-activities and use the smart apps available, as well as using home sport activities and establishing social support networks.

\section{Anger}

Staying home due to social restrictions, avoiding social interaction, and lack of social activities often leads to negative psychological energy that may result in severe negative emotions and anger. In such cases, relaxation and self-control techniques can be used, learning anger management skills, having positive cognitive beliefs and using positive self-talk will be helpful. In addition to practicing home sports activities, preoccupation with interests, recreational reading and following up targeted TV programs in a way that meets special psychological and social requirements. 


\section{Depression}

Home quarantine leads to a restriction in daily life activities. This results in a lack of activities that a person was practicing daily. A decrease in exercise activities results in a change in the emotional state that may lead to sadness, depression and negative thinking.

\section{Sleep disturbances}

Home and community quarantine may result in a change in sleep habits due to the lack of early waking and going to work. This reflects negatively on sleep behavior, which may be disturbed as a person does not sleep in the hours that he used to practice previously, and this change may result in psychological problems such as anxiety, depression, smoking, and so forth.

\section{Social effects}

The COVID-19 resulted in a lack of or even the restriction of social uniforms, because social relations and visits contribute to spreading the virus. These effects have a negative impact on the quality of life for individuals and increased psychological stress, tension and social anxiety. As social relations, visits and meeting friendships can reduce anxiety and reduce emotions, it's necessary to rethink with other alternatives available. In such cases, it is advised to establish social support networks by using smart apps, practicing home sports and social activities, and self-regulation [21]. Furthermore, it's appropriate to developing a pattern of positive self-talk, using creative problem-solving skills, and learning stress management skills.

Economic impacts and its psychological influence: in some countries COVID-19 resulted in loss of jobs and a reduction in the level of income. This may have negative effects on the psychological side; especially individuals are accustomed to a certain lifestyle and have adjusted their livelihood to their income. This may lead to restriction on daily life and social activities that in turn negatively affects psychological and social life of the people. Such condition raises the level of psychological stress, social anxiety and future anxiety. Thus, it is possible to search for new sources of income and think of ways to compensate the income or job loss, such as using the Internet to search for new work or marketing personal job competencies. In addition to use creative problem-solving, positive self-talk, reduce the level of psychological stress, and think about practical solutions in consultation with experienced and family members.

\section{Discussion and Recommendations}

COVID-19 virus negatively affected the quality of life of individuals. Despite of importance the medical health services to treat infected cases and prevent the virus and prevent its spread, the psychological services are also important. As the virus led to negative effects on mental health, these effects varies in nature and intensity from one person to another, it is necessary to educate individuals in society about how to deal with psychological problems that may result from home quarantine. However, psychological problems negatively affect the quality of life and may also exacerbate these challenges. In light of this, it is important to provide specialized psychological services, especially to those who are vulnerable to these problems, as well as educating the community about potential psychological effects and how to cope with them.

\section{References}

1. World Health Organization (WHO) (2020) Coronavirus disease (COVID-19) advice for the public.

2. Centers for Disease Control and Prevention (CDC) (2020) Coronavirus disease 2019 (COVID-19): How to protect yourself \& others.

3. World Health Organization (WHOa) (2020) Mental health and COVID-19.

4. Centers for Disease Control and Prevention (CDC) (2020a) Coping with stress.

5. Güzel P, Yildiz K, Esentas M, Zerengök D (2020) Know-How to spend time in home isolation during COVID-19, restrictions and recreational activities. International Journal of Psychology and Educational Studies 7 (2): 122-131.

6. Hagerty S, Williams L (2020) The impact of COVID-19 on mental health: The interactive roles of brain biotypes and human connection. Brain, Behavior, \& Immunity-Health Volume 5.

7. Serafini G, Parmigiani B, Amerio A, Aguglia A, Sher L, et al. (2020) The psychological impact of COVID-19 on the mental health in the general population. QJM: An International Journal of Medicine, hcaa201.

8. Vindegaard N, Benros M (2020) COVID-19 pandemic and mental health consequences: Systematic review of the current evidence. Brain Behav Immun.

9. Tarlton D (2020) Addressing mental health during COVID-19. United Nations Development Programme (UNDP), USA.

10. Cheng X (2020) Challenges of schools out, but classes on to school education: Practical exploration of chinese schools during the covid-19 pandemic. Sci Insigt Edu Front 5(2): 501-516.

11. Alreihani S, El-Zraigat I, Tannous A (2018) Counseling special needs and their families. Dar AlFiker, Amman, Jordan.

12. American Psychological Association (APA) (2020) How COVID-19 impacts people with disabilities: Research shows people with disabilities are at risk for mental health problems.

13. El-Zraigat I, Alshammari M (2020) The psychological and social effects of COVID-19 outbreak on persons with disabilities. Canadian Social Science 16(6).

14. Government of South Australia (2020) Mental health impacts of coronavirus (COVID-19). Government of South Australia COVID-19 website.

15. Haynes H (2020) Coronavirus: Disabled people forgotten by government strategy. BBC News.

16. (2020) Supplemental fact sheet: Addressing the risk of COVID-19 in preschool, elementary and secondary schools while serving children with disabilities. Office for Civil Rights, US Department of Education.

17. (2020) Fact sheet: Addressing the risk of COVID-19 in schools while protecting the civil rights of students. Office for Civil Rights, US Department of Education.

18. (2020) Coronavirus and the social impacts on Great Britain. Office for National Statistics.

19. Ryan F (2020) Coronavirus has made it even easier to forget about disabled people. 
20. Ubani K (2020) COVID-19, culture and public health conditions in developing countries: Prevention is better than cure. Canadian Social Science 16(4): 14-19.
21. United Nation (2020) COVID-19 outbreak and persons with disabilities. Department of Economic and Social Affairs Disability.

For possible submissions Click below:

Submit Article 